\title{
FIRST RECORD AND STUDY OF PREHISTORIC SACRA FROM CENTRAL NARMADA VALLEY (M.P.)
}

\author{
Anek R. Sankhyan ${ }^{1,2}$.
}

${ }^{1}$ Sr. Anthropologist (Physical) \& Visiting Fellow, Anthropological Survey of India, Kolkata (Rtd.).

${ }^{2}$ President, Palaeo Research Society, IPH Colony, Ghumarwin, H.P., 174021, India.

\section{ABSTRACT}

Aim: To report the first ever made discovery of two 70,000 years- old prehistoric fossil sacra along with their detailed comparative morphometric study with modern human sacra to see any pattern of difference between the modern and prehistoric sacra.

Methods: In all 22 parameters were used for the metric analysis of the two fossil sacra which include 17 linear and curved measurements and five indices, and six were used as sexing criteria. These were compared with those of the extant Indian populations.

Results: The two fossil sacra show some morphological difference from the modern human sacra in having less posterior curvature, and squarer outline of the male and rectangular of the female sacrum. They also exhibit very distinct sexual dimorphism in sacral index, though metric variables are within modern human range.

Conclusion: There are noticeable differences between the fossil sacra and typical modern human sacra, more so among the sexes indicating as if early humans were highly dimorphic sexually since ca.70-80 kya.

KEY WORDS: Fossil Sacra, morphometric comparison, Sacral Index, sexual dimorphism, Narmada valley.

Address for Correspondence: Dr. Anek R. Sankhyan, Palaeo Research Society, IPH Colony, Ghumarwin (H.P.) - 174021, India. Phone: +918894166565; E-Mail:arsankhyan@gmail.com

\section{Access this Article online}

\begin{tabular}{|c|c|c|}
\hline \multirow{2}{*}{$\begin{array}{l}\text { Quick Response code } \\
\text { (1) }\end{array}$} & \multicolumn{2}{|c|}{$\begin{array}{l}\text { Web site: International Journal of Anatomy and Research } \\
\text { ISSN 2321-4287 } \\
\text { www.ijmhr.org/ijar.htm }\end{array}$} \\
\hline & $\begin{array}{l}26 \text { May } 2017 \\
\text { ew: } 27 \text { May } 2017\end{array}$ & $\begin{array}{l}\text { Acc } \\
\text { Puk }\end{array}$ \\
\hline & Revised: None & Published (P): 31 Jul 2017 \\
\hline
\end{tabular}

\section{INTRODUCTION}

Human evolution in South Asia has been greatly understood through the fossil remains of the Central Narmada valley (Madhya Pradesh) which stands alone for having gifted us unambiguous Middle to Late Pleistocene (300-30 Kya) hominin (prehistoric non-modern humans) fossils in association with numerous mammalian fauna and Palaeolithic implements. First discovery of human fossils from the Central Narmada valley was of partial calvaria (Sonakia 1984) [1], followed by two clavicles and a $9^{\text {th }}$ rib (Sankhyan 1997a, b, 2005) [2, 3, 4] made during 1980s. Extensive explorations and excavations were conducted by the author and associates from the Anthropological Survey of India during 2005 to 2010, through which huge collections of fossils and archaeological assemblages were made. A preliminary scrutiny made in 2011 led to the discovery of two new human fossils of humerus and a femur (Sankhyan et al 2012a, b) $[5,6]$. But, it is only recently, that the author got the opportunity as a Visiting Fellow to re-scrutinize the fossil collection in December 2015 through February 2016. As a result he recognized a number of more human postcranial remains, including the two sacra which are studied and results reported here. 


\section{MATERIALS AND METHODS}

The present report presents an illustrated account of the two newly discovered human fossil sacra housed in the Anthropological Survey of India Kolkata and bearing the museum numbers as: NTK-F-24-05 (male) and NTK-F65-06 (female). The fossils are described systematically by following anatomical nomenclature used in Gray's Anatomy [10] and other anatomical texts, including the $\mathrm{MCT}$ scans and photographic images. Their statistical analysis has been done for calculating various indices by taking linear measurements using Mititoyo Vernier caliper. In all 22 parameters were used for the metric analysis of the two fossil sacra which include 17 linear and curved measurements and five indices, and six were used as sexing criteria following Sachdeva et al (2011) [11], Patel et al. (2005) [12], Davivongs (1963) [13], Asthana et al (2014) [14] and others. A metric comparison was made with those of the extant Indian populations.

\section{RESULTS AND OBSERVATIONS}

Geological Setting of the Fossil Sacra: The two sacra were recovered from near village Netankheri $\left(22^{\circ} 50^{\prime} 25^{\prime \prime} \mathrm{N}, 77^{\circ} 53^{\prime} 6^{\prime \prime} \mathrm{E}\right)$ from which a humerus and a femur was reported earlier (Sankhyan et al. 2012a, b). It is located along the right bank of Narmada River in Budhni sub-division of Sehore district, $25 \mathrm{~km}$ east of Shahganj town. The lithostratigraphy here is comprised of the major part of the cemented gravel beds (U1, U2, U3) of the Surajkund Formation, and the concretionary brown clays of the overlying Baneta Formation. The lower gravel bed (U1) is partially submerged in the river along with a yellowish calcareous sandy layer from which the femur fragment was discovered. The total exposed section at Netankheri is $19.2 \mathrm{~m}$ thick. From the base upwards it is constituted by yellowish calcareous sand $(0.5 \mathrm{~m})$ and overlain by $0.2 \mathrm{~m}$ thick cemented gravel bed (U1), almost submerged. It is this bed which is the same as the U1 at Hathnora (calvarium horizon) and has yielded a robust archaic femur reported earlier (Sankhyan 2010, 2015, 2016; Sankhyan et al 2012a, b) [5 - 9]. It is followed by interlayered sequences of yellowish brown coarse sand and pebbly layers $(0.6 \mathrm{~m}), 0.4 \mathrm{~m}, 1 \mathrm{~m}$, and $1 \mathrm{~m}$ cemented gravel bed (U2 and U3) of the Surajkund Formation (abbreviated as SJK Fm.). The inter-junction of the U2/U3 bed has yielded many bone tools, the reported humerus and the two sacra under reporting here. The collapsed U3 contains the lithic fragments of sandstone and the volcanic materials like jasper, quartzite, chert, agate in plenty, besides some quartzite pebbles. Above this, the lithofacies of the Baneta formation are distinctly visible by their fine brown calcareous clayey silt with grey crossbedded sand lenses $(2 \mathrm{~m})$ followed by brown silty clay $(13.5 \mathrm{~m})$.

Bio-stratigraphically and in consideration of the Youngest Toba Ash datum, the fossil sacra could be dated between 70 and 80 Kya (Sankhyan, 2012a, b) $[8,9]$.

Morphological Description of the Fossil Sacra: The term 'sacrum' (os sacrum) is derived from Latin root 'sacred' and 'sacrifice' and the Greeks believed that, besides being the seat of the sex organs, the sacrum is where the soul resides, such that the practice of animal tail sacrifice came into vogue in primitive societies. Before describing the fossil sacra it is worthwhile to mention about the modern sacrum; it is a triangular bone inserted like a wedge between the two innominate bones, the upper part (base) articulating with the last lumbar vertebra and the apex with the coccyx. Its natural curve makes it kyphotic- curving upon itself anteriorly and placed very obliquely. Sacral base projects forward forming the prominent sacro-vertebral angle when articulated with the last lumbar vertebra, and the central part projects backward enhancing the pelvic cavity. Sacroiliac joint / auricular surfaces articulate with the os coxae's corresponding auricular surfaces.

The Male Sacrum (NTK-F-24-05): Unlike the typical triangular and curved modern sacrum, it is nearly squarish and with no apparent curve, though some change in curvature may also be attributed to fossilization in the conglomeratic gravel matrix that fills the sacral foramina and the curved area. The right side the auricular surface is preserved and is quite thick and filled with. The left auricular surface is broken as the lateral and median sacral crests are damaged such that the sacral hiatus is inconspicuous and the apex turned backwards resulting in slight 
reduction and reversion of the sacral curvature, and the sacral foramina displaced and compressed. The anterior (pelvic) and posterior (caudal) sacral foramina openings are mostly obliterated and fused. The alae margins have become blunt due to rolling. But, we can observe its typical five vertebrae fused together. Two foramina are very distinct on the left side dorsally but one distinct ventrally on the anterior surface since the right lateral crest is preserved. The transverse lines or the horizontal ridges formed by the fusion of the vertebrae are visible on the anterior aspect. The superior articular facets of the S1 have two flat facets at the onset of the posterior sacral crests. But, the projections of the superior articular processes are broken, which articulate with the corresponding facets on the L5.

The dorsal wall and surface (facies dorsalis) is broken in NTK sacra and the superior articular facets are at the top, marking the superior border on the posterior aspect. In normal preserved sacrum the posterior aspect is relatively rougher with the median crest/spine that comes off the dorsal wall. The dorsal or caudal surface is convex and narrower than the pelvic or anterior surface. The left lateral and the middle crests are broken. The shallow sacral groove (for multifidus) present on either side of the middle sacral crest is difficult to distinguish due to breakage. The laminæ of the fourth sacral vertebra meet behind. The sacral cornua have tilted to the side such that the sacral hiatus is appears inconspicuous and shallow. The backward twist of the bar-like apex of the 5 th vertebra has also obliterated the apical shape and morphology. On the lateral side of the posterior sacral foramina in NTK-F-24-05 is a series of tubercles, which represent the transverse processes of the sacral vertebrae, and form the prominent right lateral crest of the sacrum (the left -side crest is broken). The transverse tubercles of the first sacral vertebra are large and very distinct. The median crest/ spine- a midline projection formed from the fused laminae of the vertebrae is broken in the NTK-F-24-05 specimen with a little remnant at the top and near the bottom. A big pebble is still embedded in the middle of the median crest which has broken the crest. Unlike the normal ventral surface smooth and concave on the anterior (ventral) aspect with visible transverse lines the concavity in NTK-F-24-05 is shallow due to, the backward twist of the lower border of the apex resulting in reverse posterior backward curvature.

The vertebral sacral canal (canalis sacralis), which runs throughout the greater part of the bone, is not preserved in NTK-F-24-05 such that its further details are difficult to observe. More details are difficult to observe due to breakage.

Fig. 1: NTK-F-24-05: Male Sacrum in a. posterior, b. lateral (left), c. anterior, d. cranial, e. lateral, f. lateral (right with reoriented apex) views.
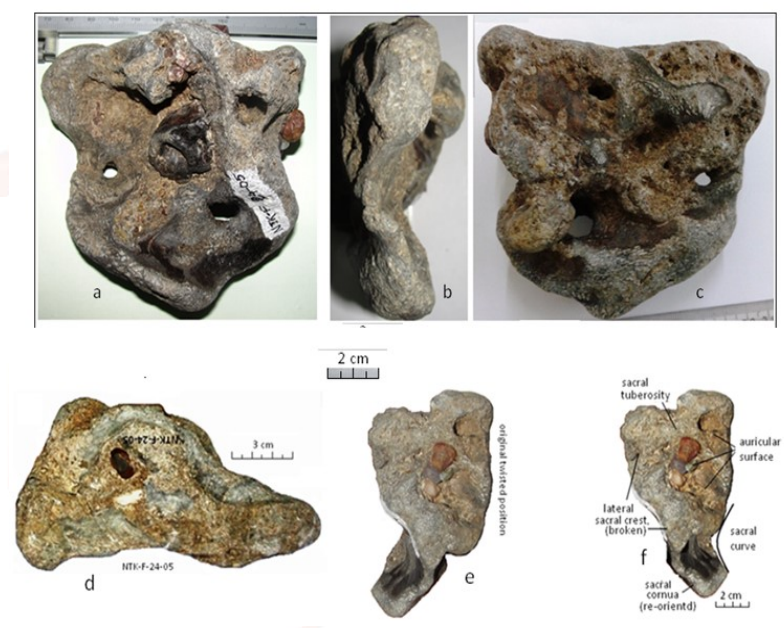

The Female Sacrum (NTK-F-65-06): It is rectangular and its right auricular surface is quite thin as the lateral and median sacral crests are broken dorsally (posteriorly). The left lateral crest is also damaged dorsally barring the apex, which presents a distinct sacral hiatus. Its auricular surfaces are narrower compared to NTK-F-24-05. The presence of four vertebrae is noted such that the bone appears much shorter and rectangular than the normal modern human sacrum. The anterior (pelvic) and posterior (caudal) sacral foramina openings are obliterated and fused or filled with matrix. The laminæ of the fourth sacral vertebra fail to meet behind and the apex (apex oss. sacri) split forming an inverted U-shaped sacral hiatus. The articular processes of the first sacral vertebra are broken and grounded by the sedimentary regime, but their facets are concave and prominent. The tubercles which represent the inferior articular processes of the 4 th/5th sacral vertebra are prolonged downward as rounded apical processes. The apex (apex oss. sacri) is bifid 
and its tendon attaches to the sphincter ani externus. The sacral cornua are prominent and separated. A pebble is embedded in the middle of the median crest but rugged and obliquely placed. The sacral segments got blended with the bodies pronouncedly and attest the adult age at death. The vertebral sacral canal (canalis sacralis), which runs throughout the greater part of the bone, is not visible as covered with matrix in NTK-F-65-06. The lateral surface is broad above but narrowed into a thin edge below.

\section{METRIC STUDY AND DISCUSSION}

The metric landmarks for measurements are illustrated in Figure 3 (middle). The metric data are presented in Table 1, and the comparative measurements and indices presented in Table 2.

Fig. 2: NTK-F-65-06: Female Sacrum in A. anterior, P. posterior, C \& C' cranial
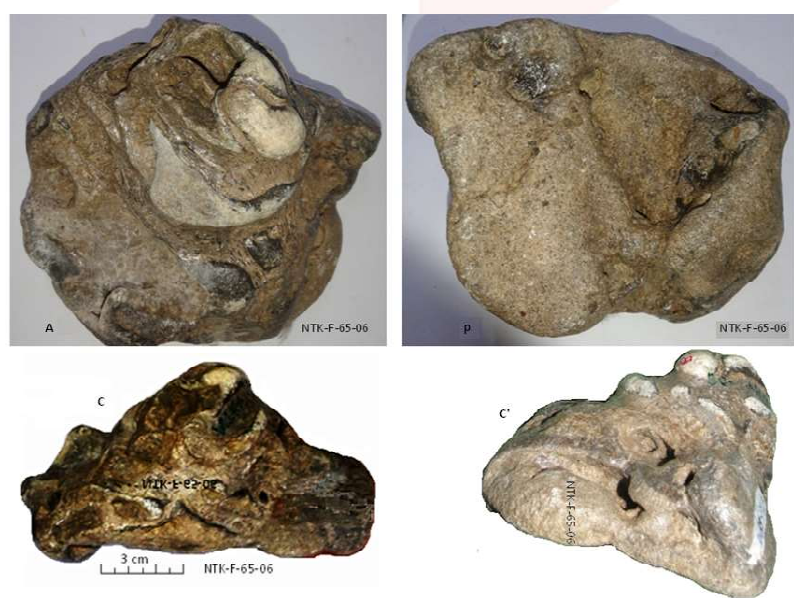

It may be noted from the comparative measurements and indices presented in Table 1 and 2 that the metrical values for most of the parameters of the Narmada sacra fall within the range of the modern humans. It is only the breadth of alae $\left(E-E^{\prime}+F F^{\prime}\right)$ which exceeds the modern range limit of male (2.6 - 4.2) and female (2.6 - 4.0) in both fossil sacra- NTK-F-24-05 (7.15) and NTK-F-65-06 (6.5). This could be an interesting difference and need to be proved further. Thus, barring the distortion, the fossil sacra are modern in size and morphology.

The Aging and Sexing: Both NTK sacra are of the adult as the five sacral vertebrae in NTK-F24-05 and four in the NTK-F-65-06 are totally fused. The sacral foramina in NTK-F-65-06 are obliterated completely whereas only two are clearly visible in the NTK-F-24-05. The probable
Table 1: Metric study of the Netankheri fossil sacra NTKF-24-05 (male) and NTK-F-65-06 (female).

\begin{tabular}{|c|c|c|c|}
\hline SI No. & Measurement $(\mathrm{cm})$ & NTK-F-24-05 & NTK-F-65-06 \\
\hline 1 & Max ventral Length $A-B$ & 10.52 & 8.3 \\
\hline 2 & Max ventral curve Length $A^{\prime}-B^{\prime}$ & 10.6 & 9 \\
\hline 3 & Max ventral breadth (TD at $1^{\text {st }}$ segment (S1) C-D & 10.54 & 10.7 \\
\hline 4 & Max promontory breadth E-F & 11.13 & 10.9 \\
\hline 5 & Max width of the centrum base (body) of S1 $E^{\prime}-F^{\prime}$ & 4 & 4.5 \\
\hline 6 & Diameter A-L & 4.68 & 4.35 \\
\hline 7 & Width of alar wing E-E' & $\begin{array}{c}L=2.8 \\
R=4.35\end{array}$ & $\begin{array}{l}\mathrm{L} 2.7 \\
\mathrm{R} 3.8\end{array}$ \\
\hline 9 & Total width of both alar $L=R$ wings $E-E^{\prime}+F-F^{\prime}$ & 7.15 & 6.5 \\
\hline 8 & TD at $2^{\text {nd }}$ crest segment $(S 2)$ & 9.37 & 9.5 \\
\hline 10 & TD at 3rd crest segment (S3) & 8.85 & 9.6 \\
\hline 10 & TD at 4th crest segment (S4) & 9.24 & 6.36 \\
\hline 11 & TD at 5th crest segment (S5) & 6.9 & - \\
\hline 12 & A-P Thickness at the ala of $1^{\text {st }}$ segment (S1) & $\begin{array}{c}1.7 \text { (broken) } \\
\text { R } 6.07\end{array}$ & $\begin{array}{l}\mathrm{L} 1.77 \\
\text { R } 3.6\end{array}$ \\
\hline 13 & A-P Thickness at the $2^{\text {nd }}$ segment $(\mathrm{S} 2) /$ lateral crest & $\begin{array}{l}\text { L } 1.24 \\
\text { R } 5.74\end{array}$ & $\begin{array}{l}\text { L2.32 } \\
\text { R } 2.57\end{array}$ \\
\hline 14 & A-P Thickness at the 3rd segment (S3)/ lateral crest & $\begin{array}{l}L 0.6 \\
R 6.2\end{array}$ & $\begin{array}{l}\text { L } 1.57 \\
\text { R } 3.24\end{array}$ \\
\hline 15 & A-P Thickness at the $4^{\text {th }}$ segment (S4)/ Apex & $\begin{array}{l}\text { L } 0.82 \\
\text { R } 1.1\end{array}$ & $\begin{array}{l}\text { L1.24 (Apex) } \\
\text { R 2.24 (Apex) }\end{array}$ \\
\hline 16 & A-P Thickness at the $5^{\text {th }}$ segment (S5) or Apex & $\begin{array}{l}\text { R } 1.33 \\
\text { L } 1.6\end{array}$ & - \\
\hline 17 & Depth (D) and max width (W) of the sacral hiatus & - & $\begin{array}{l}\text { D } 2.2 \\
\text { W } 2.0\end{array}$ \\
\hline 18 & Sacral Index $=C D / A B \times 100$ & 100.19 & 128.92 \\
\hline 19 & Longitudinal Curvature Index $=A B / A^{\prime} B^{\prime} \times 100$ & 99.25 & 92.22 \\
\hline 20 & Corporobasal Index $=E^{\prime}-F^{\prime} / E-F x 100$ & 35.94 & 41.28 \\
\hline 21 & $\begin{array}{l}\text { Kimura's base-wing index (= Alar index): E-E' / } E^{\prime}-F^{\prime} \\
\times 100 \text {; Width of alar wing X } 100 \text { / transverse diameter } \\
\text { of body of } S 1\end{array}$ & $\begin{array}{l}\text { L } 70.0 \\
\text { R } 108.74\end{array}$ & $\begin{array}{l}\text { L } 60.0 \\
\text { R } 87.36\end{array}$ \\
\hline 22 & Depth and maximum width of the sacral hiatus & - & $2.2 \& 1.7$ \\
\hline
\end{tabular}

age could be above 40 years at death. There is strong evidence of mineralization during fossilization in the both which speaks for considerable antiquity.

In general the female sacrum is shorter and wider; the lower half forms a greater angle with the upper; the upper half is nearly straight, the lower half presenting the greatest amount of curvature. The bone is also directed more obliquely backward; this increases the size of the pelvic cavity and renders the sacrovertebral angle more prominent. In the male the curvature is more evenly distributed over the whole length of the bone, and is altogether greater than in the female. The sacrum is an important bone for identification of sex in 
Table 2: Comparative metric study of the Netankheri fossil and modern human sacra after Sachdeva et al [11].

\begin{tabular}{|c|c|c|c|c|c|c|}
\hline Sr. No. & Measurement (in cm) & $\begin{array}{l}\text { NTK-F-24-05 } \\
\text { (M) }\end{array}$ & NTK-F-65-06 (F) & Sex & Mean + S.D. & Range \\
\hline \multirow{2}{*}{1} & \multirow{2}{*}{$\begin{array}{l}\text { Mid ventral Straight Length/height } \\
(\mathrm{cm}) \text { A-B }\end{array}$} & \multirow{2}{*}{10.52} & \multirow{2}{*}{8.3} & $\mathrm{M}$ & $10.4 \pm 1.3$ & $6.8-13.1$ \\
\hline & & & & $\mathrm{F}$ & $9.2 \pm 0.7$ & $8.3-10.7$ \\
\hline \multirow{2}{*}{2} & \multirow{2}{*}{ Mid ventral Curved Length $A^{\prime}-B^{\prime}$} & \multirow{2}{*}{10.6} & \multirow{2}{*}{9} & $M$ & $11.4 \pm 1.1$ & $9.6-14.1$ \\
\hline & & & & $\mathrm{F}$ & $10.5 \pm 0.6$ & $9.8-11.6$ \\
\hline \multirow{2}{*}{3} & \multirow{2}{*}{$\begin{array}{l}\text { Ventral Straight breadth or Transverse } \\
\text { Diameter of base C-D }\end{array}$} & \multirow{2}{*}{10.54} & \multirow{2}{*}{10.7} & M & $10.31 \pm 0.8$ & 8.7- 11.9 \\
\hline & & & & $\mathrm{F}$ & $10.2 \pm 0.7$ & $9.5-11.8$ \\
\hline \multirow{2}{*}{4} & \multirow{2}{*}{ TD Base at S1 E-F } & \multirow{2}{*}{11.13} & \multirow{2}{*}{10.9} & M & $11.2 \pm 0.8$ & $9.7-13.6$ \\
\hline & & & & $\mathrm{F}$ & $10.4 \pm 0.8$ & $9.5-11.9$ \\
\hline \multirow{2}{*}{5} & \multirow{2}{*}{ TD Body S1 E-F' } & \multirow{2}{*}{4} & \multirow{2}{*}{4.5} & $M$ & $4.8 \pm 0.7$ & $1.4-6.5$ \\
\hline & & & & $\mathrm{F}$ & $4.6 \pm 0.5$ & $3.9-5.5$ \\
\hline \multirow{2}{*}{6} & \multirow{2}{*}{ A-P Diameter Body S1 A-L } & \multirow{2}{*}{4.68} & \multirow{2}{*}{4.35} & $M$ & $3.2 \pm 0.41$ & $2.4-4.4$ \\
\hline & & & & $\mathrm{F}$ & $2.85 \pm 0.2$ & $2.6-3.3$ \\
\hline \multirow{2}{*}{7} & \multirow{2}{*}{ Breadth of Alae E-E' + FF' } & \multirow{2}{*}{7.15} & \multirow{2}{*}{6.5} & $\mathrm{M}$ & $3.5 \pm 0.4$ & $2.6-4.2$ \\
\hline & & & & $\mathrm{F}$ & $3.0 \pm 0.4$ & $2.6-4.0$ \\
\hline \multirow{4}{*}{8} & \multirow{4}{*}{$\begin{array}{l}\text { Sacral Index (\%) Ventral Straight } \\
\text { breadth or Transverse } \\
\text { Diameter/Vertical length or height } \\
\text { CD/AB } \times 100\end{array}$} & \multirow{4}{*}{100.19} & \multirow{4}{*}{128.92} & M & $100.2 \pm 12.5$ & 78.0 - 149.6 \\
\hline & & & & $\mathrm{F}$ & $111.7 \pm 14.6$ & $88.8-140.5$ \\
\hline & & & & $M * 20$ & $\begin{array}{l}96.2 \pm 4.6 \\
\left(\mathrm{Dp}^{\#}<96.0\right) \\
\end{array}$ & $82.5-110.1$ \\
\hline & & & & $F * 22$ & $\begin{array}{c}113.25 \pm 5.7 \\
(d p>110.1)\end{array}$ & $96.0-130$ \\
\hline \multirow[t]{2}{*}{9} & $\begin{array}{l}\text { Longitudinal Curvature Index (\%) } \\
A B / A^{\prime} B^{\prime} x 100\end{array}$ & 99.25 & 92.22 & M & $91.59 \pm 6.4$ & $71.0-112.3$ \\
\hline & & & & $\mathrm{F}$ & $87.87 \pm 5.8$ & 80.4- 98.1 \\
\hline 10 & Corporo-basal Index (\%) E'F'/EF x100 & 35.94 & 41.28 & M & $43.2 \pm 4.3$ & 32.9- 54.81 \\
\hline & & & & $\mathrm{F}$ & $43.8 \pm 5.4$ & $32.8-52.4$ \\
\hline 11 & Kimura's base-wing index = Alar index: & L 70.0 & $\mathrm{~L}=60$ & $M * 6$ & $\begin{array}{c}\mathrm{L} 62.2 \pm 12.6 \\
(\mathrm{dp}<48) \\
\mathrm{R} 61.6 \pm 11.7 \\
(\mathrm{dp}<43.7)\end{array}$ & $\begin{array}{l}\text { L } 24.23 \text { - } 100.1 \\
\text { R } 26.5 \text { - } 96.7\end{array}$ \\
\hline & transverse diameter of body of S1 & R 108.7 & $R=87.4$ & $\mathrm{~F} * 6$ & $\begin{array}{l}L 75.9 \pm 9.3 \\
(\mathrm{~d} p>100.1) \\
R 79.5 \pm 11.9 \\
(\mathrm{Dp}>96.7)\end{array}$ & $\begin{array}{l}\text { L } 48 \text { - } 103.8 \\
\text { R } 43.71-115.3\end{array}$ \\
\hline
\end{tabular}

*After Patel et al., 2005, Dp\# demarcating point, TD= transverse diameter, AP=antero-posterior diameter

Fig. 3: mCT Scans of NTK-F-24-05 male sacrum (above) and NTK-F-65-06 female sacrum (below); sacral landmarks (middle)
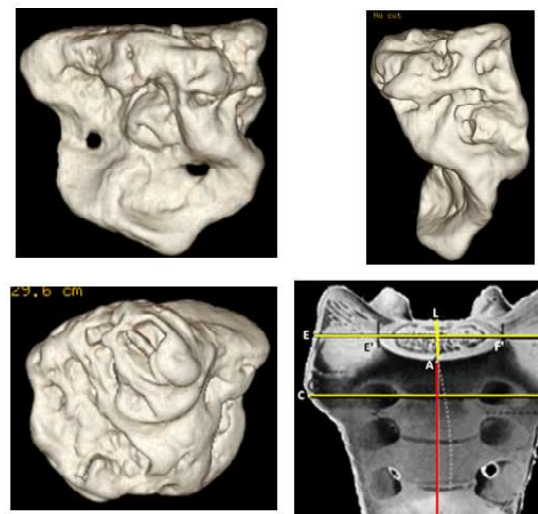
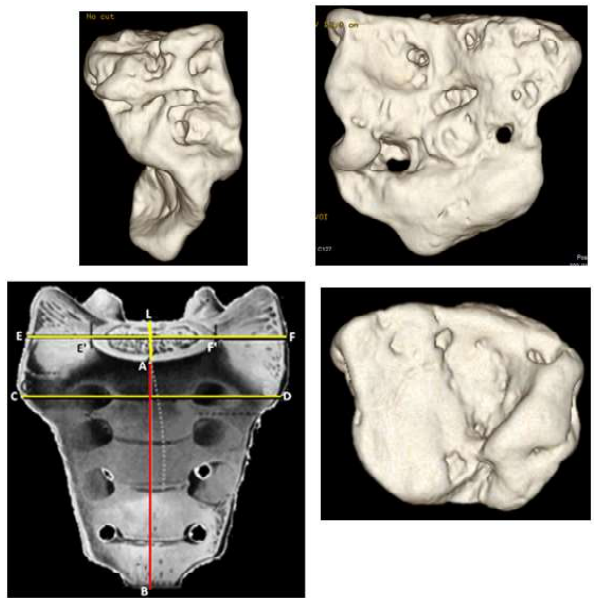
human skeletal system. Since it is a component of axial skeleton and because of its contribution to the pelvic girdle and in turn to the functional differences in the region between the sexes, it has an applied importance in determining sex with the help of measurements carried upon it. Davivongs (1963) [13], observed that as a general rule male bones are more massive and heavier than female bones, and among all metrical criteria, the five listed below show significant mean differences between the twosexes, all being higher in the males. A scrutiny of the main findings from Table 1 and Table 2 in relation to the sexing criteria of Davivongs (1963) [13], listed in Table 3 show that both the Netankheri sacra, NTK-F-24-05 and NTK-F-65-06, follow the six sexing criteria:-

Table 3: Sexing criteria and the inferred sex of the Netankheri fossil sacra.

\begin{tabular}{|c|c|c|c|c|}
\hline SI. No. & Measurement & Landmark & NTK-F-24-05 & NTK-F-65-06 \\
\hline $\mathrm{i}$ & Midventral straight length & $A-B$ & 10.52 & 8.3 \\
\hline ii & Midventral curved length & $A^{\prime}-B^{\prime}$ & 10.6 & 9 \\
\hline iii & Transverse diameter of base & $C-D$ & 10.54 & 10.7 \\
\hline iv & A-P diameter of body of $S 11$ & $A-L$ & 4.68 & 4.35 \\
\hline$v$ & Breadth of alae & $E-E^{\prime}+F F^{\prime}$ & 7.15 & 6.5 \\
\hline vi & Sacral index & $C D / A B \times 100$ & 100.19 & 128.92 \\
\hline \multicolumn{3}{|c|}{ Inferred Sex } & Male & Female \\
\hline
\end{tabular}

It is only the sixth criterion, the sacral index which is very significantly higher in NTK-F-6506 (128.92) than the NTKF-24-05 (100.19), such that the former may convincingly be identified as female, and the latter as male.

Several scholars have noticed similar results from Indian populations of different regions. Flander (1978) [15] had preferred sacral index as the better sexing criterion having lower mean value in males $(96.25 \pm 4.6)$ than the females (113.25 \pm 5.74$)$. Patel et al. (2005) [12] also noted the sacral index as better indicator of the sex than the Kimura's base-wing index. Sachdeva et al. (2011) [11] observed in Varanasi and other North Indian populations that the sex differences are more in line with the robustness of the male skeleton. In addition, they observed that the breadth of the alae and the corporobasal index gave contrasting results, the alae being wider in males and the corporobasal index higher in females, and that the transverse diameter of base of sacrum is significantly higher in males.
Sachdeva et al (2011) [11] also presented metric values for 10 parameters on Amritsar (Punjabi populations) sacra compared with present fossil sacra, and it is observed that the NTK sacra show a similar pattern. Asthana et al (2014) [14] used sacral index to differentiate the two sexes in western Indian populations of Jaipur and Bikaner (Rajasthan). Janipati et al (2014) [16] studied the sacral index among populations of Telangana and Andhra Pradesh and compared with various Indian populations and found it higher in Telangana and Andhra Pradesh. They concluded that the mean sacral index in females is higher than that of males in Indian populations. Somesh et al (2015) [17] also endorsed that the sacral index remains very useful indicator, though they suggested that other parameters, e g., sacral linear and curved lengths should also be included in sex determination. Shreekrishna et al (2013) [18] from Tamil Nadu sacra highlighted the importance of certain parameters like sacral index while also demonstrating insignificance other parameters, but basic fact remains that as far as the sex determination of sacrum is concerned no single parameter could identify sex in $100 \%$ of the bones and hence, it can be concluded that for sex determination of the sacrum with $100 \%$ accuracy is possible only when maximum number of parameters are taken into consideration. From a study on Jabalpur sacra Dube and Roy (2016) [19] also concluded that the sacral index method is more reliable and should be applied for sex determination of sacrum in various anatomical, forensic and anthropological investigations.

The sacral hiatus is commonly (86\%) inverted U-shaped as observed by Elumalai et al (2016) [20] in Nepal. The NTK female sacrum also shows a similar sacral hiatus and its penetration is up to the level of $4^{\text {th }}$ sacral vertebra, which is also a common feature $(79.38 \%)$ observed in Karnataka sacra by Shinde and Shirbadgi (2016) [21]. But, another study on Karnataka sacra by Ashok et al (2016) [22] showed much more variation in the sacral hiatus, e.g., an inverted ' $U$ ' shape in $39.09 \%$, inverted ' $V$ ' in $29.09 \%$, dumbbell in $10 \%$, bifid in $5.45 \%$, irregularly shaped in $9.09 \%$, elongated in $5.45 \%$, and total spina bifida occulta in $1.81 \%$; the sacral apex 
was located at the level of 4th sacral vertebra in $57.40 \%$, at the level of 3rd sacral vertebra in $35.18 \%$ at $2^{\text {nd }}$ sacral vertebra in $5.55 \%$ and at 5 th sacral vertebra in $1.85 \%$. They conclude that the variations in the anatomy of the sacral hiatus, is one of the reasons for the failure of caudal epidural block.

Vasuki et al (2016) [23] have recently added a new dimension and illustrated variations in the sacral hiatus and highlighted their importance to the anaesthetists, radiologists, surgeons, orthopedicians and gynaecologists since it is the site where caudal analgesia and epidural anaesthesia has been given.

\section{CONCLUSION}

The two fossil sacra show a general morphometric similarity with modern human sacra with some difference in posterior curvature and shape. They exhibit very distinct sexual dimorphism in sacral index indicating that humans were distinctively sexually dimorphic since about 70-80 Kya.

\section{ACKNOWLEDGEMENTS}

I am solely responsible for the identification of the material and present study. But, I sincerely acknowledge the field assistance given by the young explorers credited elsewhere, notably, L.N. Dewangan, Sheuli Chakravarty, Suvendu Kundu, Shashi Prabha, etc. Dr. V.R. Rao, the then D-i-C, facilitated the project and several experts imparted field orientations like, Drs. G.L. Badam, S.B. Ota, M.P. Tiwari and Y. H. Bhai. Special thanks are due to Shri G.S. Rautela, ex-Director AnSI for providing me opportunity of a Visiting Fellow that made the present study possible.

\section{Conflicts of Interests: None}

\section{REFERENCES}

[1]. Sonakia A. The skullcap of early man and associated mammalian fauna from Narmada valley alluvium, Hoshangabad area, MP (India). Rec. Geol. Surv. India 1984;113:159-172.

[2]. Sankhyan A R. Fossil Clavicle of a middle Pleistocene hominid from the Central Narmada Valley, India. J. Hum. Evol. 1997; 32: 3-16; doi: 10.1006/ jhev. 1996.0117.

[3]. Sankhyan A R. A new human fossil find from the Central Narmada basin and its chronology. Curr Sci., 1997; 73: 1110-1111.
[4]. Sankhyan AR. New fossils of Early Stone Age man from Central Narmada Valley. Curr. Sci., 2005; 88: 704-707.

[5]. Sankhyan AR. Pleistocene hominins and associated findings from Central Narmada Valley bearing on the evolution of man in South Asia, Ph. D. dissertation, Panjab University, Chandigarh, 2010.

[6]. Sankhyan AR. Pleistocene hominin fossil discoveries in India: Implications for human evolution in South Asia. In: Sankhyan, A.R. (Ed.) Recent discoveries and perspectives in human evolution, BAR International Series 2719, England: Archaeopress, 2015; pp. 41-51.

[7]. Sankhyan AR. Hominin fossil remains from the Narmada Valley. In: Robbins Schug, G., Walimbe, S. R. (Eds.) A Companion to South Asia in the Past, 1st Edn., New York: John Wiley \& Sons, Inc., 2016; pp. 72-85.

[8]. Sankhyan A R, Badam GL, Dewangan LN, Chakraborty S, Prabha S, Kundu S, Chakravarty R. New postcranial hominin fossils from the Central Narmada Valley, India. Advances in Anthropology, 2012; 2 (3): 125-131, Published Online August 2012 in SciRes. DOI:10.4236/aa.2012.23015.

[9]. Sankhyan A R, Dewangan LN, Chakraborty S, Prabha S, Kundu S, Chakravarty R, Badam GL. New human fossils and associated findings from the Central Narmada. Cur. Sci. 2012; 103 (12): 1-9.

[10].Grey's Anatomy: The Complete Sixth Season. Amazon.com. Retrieved May 27, 2012.

[11]. Sachdeva K, Singla RK, Kalsey G, Sharma, G. Role of sacrum in sexual dimorphism- A morphometric study. J. Indian Acad. Forens. Med. 2011; 33 (3): 206-210.

[12]. Patel MM, Gupta BD, Singel TC. Sexing of Sacrum by Sacral Index\& Kumra's Base- Wing index. J Ind Acad Foren Med. 2005; 27 (1):1-9.

[13]. Davivongs V. The pelvic girdle of the Australian Aborigine; sex differences and sex determination. Am. J. Phys. Anthropol. 1963; 21:443-455.

[14]. Asthana S, Gupta S, Khatri M, Agarwal GC. Sacral index is more reliable than Kimura's base wing index for sex determination of a sacrum. Nat. J. Med. Res. 2014; 4 (1): 71-74.

[15]. Flander LB. Univariate and multivariate methods for sexing the sacrum. Am. J. Phys. Anthropol. 1978; 49 (1): 103-110

[16]. Janipati P, Kothapalli J, Rao VS. Study of sacral index: comparison between different regional populations of India and abroad. International Journal of Anatomy and Research, Int. J. Anat. Res. 2014; 2(4): 640-44. ISSN 2321- 4287 DOI: 10.16965/ ijar.2014.504

[17]. Somesh MS, Sridevi HB, Murlimanju BV. An anatomical study of adult sacrum with its emphasis on its sexual dimorphism in south Indian population: an anatomical study of adult sacrum with its emphasis on its sexual dimorphism in south Indian population. Int. J. Anat. Res. 2015; 3(4):1491-96. ISSN 2321- 4287. DOI: http://dx.doi.org/10.16965/ ijar.2015.273 
[18]. Shreekrishna HK, Yatiraj S, Vijayakumari N. Credibility of VariousIndices of Sacrum in Identification of Sex of Sacrum. Int. J. Med. Toxicol. Foren. Med. 2013; 3(2): 58-63.

[19]. Dubey A, Roy SS. A comparative study of sacral index v/s kimura's base wing index in sex determination through sacrum. Int. J. Anat. Res. 2016; 4(2):2204-06. ISSN 2321-4287. DOI: http:// dx.doi.org/10.16965/ijar.2016.178

[20]. Elumalai G, Thangamani M, Sanyal S, Kanagarajan P. Deficient sacral hiatus cause mechanical low back pain: a radiological study. Int. J. Anat. Res. 2016; 4(1):1758-64. ISSN 2321-4287. DOI: http:// dx.doi.org/10.16965/ijar.2015.326
[21]. Shinde VK, Shirbadgi SA. Study of variations in levels of sacral hiatus. Int. J. Anat. Res. 2016; 4(1):188285. ISSN 2321-4287. DOI: http://dx.doi.org/ 10.16965/ijar.2016.102

[22]. Ashok KR, Kiran TV, Rohini KR. Study of sacral hiatus in dry bones. Int J Anat Res 2016; 4(2):24932497. DOI: 10.16965/ijar.2016.251

[23]. Vasuki AK Manicka, Nirmaladevi M., Hebzibah Deborah Joy, Jamuna M, Kalyana Sundaram K, Vimala V. Morphology of Sacrum and its Variations. J. Dental and Medical Sciences (IOSR-JDMS). 2016; 15 (8) Ver. II: 129-142. e-ISSN: 2279-0853, p-ISSN: 2279-0861, www.iosrjournals.org

How to cite this article:

Anek R. Sankhyan. FIRST RECORD AND STUDY OF PREHISTORIC SACRA FROM CENTRAL NARMADA VALLEY (M.P.). Int J Anat Res 2017;5(3.1):4144-4151. DOI: 10.16965/ijar.2017.270 